\title{
CD36 haplotypes are associated with lipid profile in normal-weight subjects
}

\author{
Luz E Ramos-Arellano', Aralia B Salgado-Bernabé1, Iris P Guzmán-Guzmán', Lorenzo Salgado-Goytia1,
} José F Muñoz-Valle ${ }^{2}$ and Isela Parra-Rojas ${ }^{1 *}$

\begin{abstract}
Background: Dyslipidemia is a common metabolic disorder that may result from abnormalities in the synthesis, processing and catabolism of lipoprotein particles. Disorders of lipoprotein concentrations and elevated concentration of oxidized lipoproteins (oxLDL) are risk factors in the pathogenesis of cardiovascular diseases (CVD). CD36 plays an important role in lipid metabolism and polymorphisms in the CD36 gene are related to cardiovascular risk factors. The purpose of this study was to evaluate whether there is an association between genotypes and haplotypes of five polymorphisms in the CD36 gene with lipid levels in young normal-weight subjects.
\end{abstract}

Methods: A total of 232 unrelated subjects with normal-weight of 18 to 25 years old (157 women and 75 men) were randomly selected. The lipid profile and glucose levels were measured by enzymatic colorimetric assays. Genotyping of the polymorphisms -33137A/G (rs1984112), -31118G/A (rs1761667), -22674 T/C (rs2151916), 27645 Ins/Del (rs3840546) and 30294G/C (rs 1049673) in the CD36 receptor gene was performed by polymerase chain reaction and restriction fragment length polymorphism, linkage disequilibrium analysis among the five polymorphisms and an analysis of haplotype were estimated.

Results: HDL-C levels was lower in men than in women $(P=0.03)$. However, the median oxLDL levels in men was higher than in women $(P=0.05)$. There was no significant difference in the levels of TC, TG, LDL-C and glucose $(P>0.05)$. HDL-C levels were lower in the subjects with TC genotype of polymorphism -22674 T/C $(P=0.04)$, but the carriers of $T T$ genotype had lower oxLDL levels $(P=0.01)$. LDL-C levels were higher in young carriers of CC genotype for 30294G/C polymorphism than non-carriers $(P=0.03)$. The subjects carrying the AATDC haplotype had 3.2 times presumably higher risk of $L D L-C>100 \mathrm{mg} / \mathrm{dL}$ than the carrying the AGTIG haplotype $(P=0.02)$, whereas the subjects carrying the AATIC haplotype had 2.0 times presumably higher risk of TC $>200 \mathrm{mg} / \mathrm{dL}$ than the carrying the AGTIC haplotype $(P=0.02)$.

Conclusion: The study provides evidence of a genetic association of CD36 haplotypes with the variability in LDL-C and TC levels in a sample of normal-weight subjects.

Keywords: Dyslipidemia, CD36 gene, Polymorphisms, Haplotypes

\section{Background}

Dyslipidemia is a common metabolic disorder that may result from abnormalities in the synthesis, processing and catabolism of lipoprotein particles [1]. Lipoproteins are the macromolecular vehicles for transport of hydrophobic lipids throughout the aqueous environment of the circulatory system; they are composed of various lipid species aggregated with specific proteins (apolipoproteins), which

\footnotetext{
* Correspondence: iprojas@yahoo.com

'Laboratorio de Investigación en Obesidad y Diabetes, Unidad Académica de Ciencias Químico Biológicas, Universidad Autónoma de Guerrero, Chilpancingo, Guerrero, México

Full list of author information is available at the end of the article
}

act as receptor ligands, stabilize the emulsion and confer structural properties to the lipoprotein particle [2].

Lipid transport and metabolism involves three general pathways: (1) the exogenous pathway, whereby chylomicrons are synthesized by the small intestine, and dietary triglycerides (TGs) and cholesterol are transported to various cells of the body; (2) the endogenous pathway, whereby the very low-density lipoprotein cholesterol (VLDL-C) and TGs are synthesized by the liver for transport to various tissues; in the plasma, the TGs in VLDLs are hydrolyzed by lipoprotein lipase (LPL), 
generating a series of smaller, cholesterol enriched lipoproteins: intermediate-density lipoprotein (IDL) and lowdensity lipoprotein (LDL); (3) and the reverse cholesterol transport, whereby high-density lipoprotein (HDL) in a series of metabolic steps facilitates the removal of cholesterol from the peripheral tissues for delivery to the liver and steroidogenic organs [3]. Disorders of lipoprotein concentrations such as elevated LDL-C ( $\geq 160 \mathrm{mg} / \mathrm{dL})$, low HDL-C $(<40 \mathrm{mg} / \mathrm{dL})$, increase TG $(\geq 150 \mathrm{mg} / \mathrm{dL})$ and elevated oxidized lipoproteins (oxLDL) levels are risk factors in the pathogenesis of cardiovascular diseases (CVD) [4]. However, it has been shown that atherosclerosis can begin with LDL-C levels $\geq 100 \mathrm{mg} / \mathrm{dL}$, therefore modification of lipid and lipoprotein classification identifies to LDL-C $<100 \mathrm{mg} / \mathrm{dL}$ as optimal [5].

CD36 is a polypeptide from 78 to $88 \mathrm{kDa}$ of molecular weight (50 kDa deglycosylated) depending on the cell type [6]. CD36 receptor is involved in a variety of biological processes including lipid metabolism, inflammation, atherosclerosis, angiogenesis, innate immune responses, uptake of apoptotic cells, oxidized lipids and advanced glycation end products, transforming growth factor- $\beta$ activation, insulin resistance, diabetes and thrombosis, depending on nature of the ligand and tissue or cell type on which it is expressed [7-10]. CD36 contributes to oral fat perception and intestinal chylomicron formation [11]. CD36 is a multi-ligand scavenger receptor expressed on a variety of cell types including adipocytes, myocytes, monocytes, macrophages, platelets, hepatocytes and vascular epithelial cells $[12,13]$. Given the many functions of CD36 including long chain fatty acid transport (LCFA), changes in CD36 expression and protein may lead to several disturbances including insulin resistance and dyslipidemia [14]. This receptor is up regulated by oxLDL in macrophages and contributes to the formation and accumulation of foam cells at sites of arterial lesions during early and late atherosclerosis [15].

The CD36 gene is located on chromosome $7 \mathrm{q} 11.2$, is encoded by 15 exons and spans $36 \mathrm{~Kb}$, CD36 plays an important role in lipid metabolism and its gene polymorphisms are associated to cardiovascular risk factors $[16,17]$. Genome-wide linkage scans have identified nearby regions of chromosome 7 that are associated with features of metabolic syndrome, such as triglyceride concentrations, HDL-C, and triglyceride/HDL ratio [18].

The aim of this study was to evaluate whether there is an association between genotypes and haplotypes of five polymorphisms in the CD36 gene with lipid levels in normal-weight young men and women.

\section{Results}

\section{General and biochemical characteristics}

General and biochemical characteristics of study subjects according to gender are shown in Table 1. The measurements of body weight, height, systolic blood pressure,
Table 1 Clinical characteristics and lipid levels by gender

\begin{tabular}{llll}
\hline Variables & Female $(\mathbf{n}=\mathbf{1 5 7})$ & Male $(\mathbf{n}=\mathbf{7 5})$ & $\boldsymbol{P}$ value \\
\hline Age $($ years $)$ & $21(19-22)$ & $20(20-22)$ & 0.433 \\
Weight $(\mathrm{kg})$ & $52(48-56)$ & $63(57-68)$ & 0.001 \\
Height $(\mathrm{cm})$ & $156(152-159)$ & $169(166-173)$ & 0.001 \\
BMI $\left(\mathrm{kg} / \mathrm{m}^{2}\right)$ & $22(20-23)$ & $22(20-23)$ & 0.411 \\
SBP $(\mathrm{mmHg})$ & $102(97-106)$ & $110(103-119)$ & 0.001 \\
DBP $(\mathrm{mmHg})$ & $66(60-71)$ & $68(61-72)$ & 0.299 \\
Hypertension $(\%)$ & $4(3)$ & $8(11)$ & 0.009 \\
TC $(\mathrm{mg} / \mathrm{dL})$ & $75(58-102)$ & $77(57-19)$ & 0.926 \\
HDL-C (mg/dL) & $48(38-58)$ & $42(37-52)$ & 0.032 \\
LDL-C (mg/dL) & $93(67-118)$ & $89(70-116)$ & 0.311 \\
OxLDL (U/L) & $34(27-46)$ & $39(31-53)$ & 0.053 \\
TG $(\mathrm{mg} / \mathrm{dL})$ & $75(58-103)$ & $77(57-109)$ & 0.926 \\
Glucose $(\mathrm{mg} / \mathrm{dL})$ & $81(75-88)$ & $81(75-88)$ & 0.942 \\
\hline
\end{tabular}

$S B P$, Systolic blood pressure; $D B P$, Diastolic blood pressure; $T C$, Total cholesterol; HDL-C, High-density lipoprotein cholesterol; LDL-C, Low-density lipoprotein cholesterol; oxLDL, Oxidized low-density lipoprotein; $T G$, Triglyceride. The values were presented as median (percentile $25-75^{\text {th }}$ ). The difference between genders was determined by the Wilcoxon-Mann-Whitney test. Data of hypertension were presented in $(\mathrm{n})$ and the percentages; the difference between genders was determined by chi-square test.

prevalence of hypertension and oxLDL levels were higher in men than in women $(P<0.05)$, whereas HDL-C levels was lower in men than in women $(P=0.03)$. There was no significant difference in the levels of TC, TG, LDL-C and glucose $(P>0.05)$.

\section{Genotypic and allelic frequencies}

Table 2 shows the genotype and allelic distribution of five CD36 polymorphisms in normal-weight subjects, genotype frequencies of each polymorphism were in Hardy-Weinberg equilibrium. The 27645Ins/Del polymorphism was found high linkage disequilibrium (LD) with $-31118 \mathrm{G} / \mathrm{A}$ and $-22674 \mathrm{~T} / \mathrm{C}$ polymorphisms; while the $-33137 \mathrm{~A} / \mathrm{G}$ and $-31118 \mathrm{G} / \mathrm{A}$ polymorphisms were also found in high LD (Figure 1).

As shown in Table 3, the levels of HDL-C were lower in the -22674 TC carriers $(P=0.04)$, but the subjects with TT genotype for this same polymorphism had lower oxLDL levels than non-carriers $(P=0.01)$. LDL-C levels were higher in $30294 \mathrm{CC}$ carriers than non-carriers $(P=0.03)$.

\section{Haplotypes and dyslipidemia susceptibility}

To examine the combined effect of five variants -33137A/G (rs1984112), -31118G/A (rs1761667), -22674 T/C (rs2151916), 27645Ins/Del (rs3840546) and 30294G/C (rs1049673) in the CD36 receptor gene locus, we performed haplotype analysis considered the combinations most frequent (Table 4). In particular, the subjects with AATDC (12122) haplotype had 3.2 times higher risk of LDL-C $>100 \mathrm{mg} / \mathrm{dL}$ than the carrying the 
Table 2 Allele and genotype frequencies in normal-weight subjects

\begin{tabular}{|c|c|c|c|c|c|}
\hline Polymorphism & Genotype n (\%) & Allele & n (\%) & HWE $X^{2}$ ( $P$ value) & Location \\
\hline$-33137 A / G$ & & & & & $5^{\prime}$ flanking exon $1 \mathrm{~A}$ \\
\hline AA & $117(50)$ & A & $328(0.71)$ & $0.11(0.73)$ & \\
\hline AG & $94(41)$ & G & $136(0.29)$ & & \\
\hline GG & $21(9)$ & & & & \\
\hline$-31118 \mathrm{G} / \mathrm{A}$ & & & & & $5^{\prime}$ flanking exon $1 \mathrm{~A}$ \\
\hline GG & $46(20)$ & G & $196(0.42)$ & $1.53(0.21)$ & \\
\hline GA & $104(45)$ & A & $268(0.58)$ & & \\
\hline AA & $82(35)$ & & & & \\
\hline$-22674 \mathrm{~T} / \mathrm{C}$ & & & & & Promoter \\
\hline$\pi$ & $106(46)$ & $\mathrm{T}$ & $309(0.67)$ & $0.84(0.35)$ & \\
\hline TC & $97(42)$ & C & $155(0.33)$ & & \\
\hline CC & $29(12)$ & & & & \\
\hline 27645Ins/Del & & & & & Exon 14 (3'-UTR) \\
\hline Ins/Ins & 206 (89) & Ins & $437(0.94)$ & $0.06(0.79)$ & \\
\hline Ins/Del & 25 (10.6) & Del & $27(0.06)$ & & \\
\hline Del/Del & $1(0.4)$ & & & & \\
\hline $30294 G / C$ & & & & & Exon 15 (3'-UTR) \\
\hline GG & $13(6)$ & G & $111(0.24)$ & $0.01(0.92)$ & \\
\hline GC & $85(36)$ & C & $353(0.76)$ & & \\
\hline CC & $134(58)$ & & & & \\
\hline
\end{tabular}

HWE, Hardy-Weinberg Equilibrium.

AGTIG (11111) haplotype $(P=0.02)$, whereas the subjects carrying the AATIC (12112) haplotype had 2.0 times presumably higher risk of TC $>200 \mathrm{mg} / \mathrm{dL}$ than the carrying the AGTIC (11112) haplotype $(P=0.02)$.

\section{Discussion}

The results of the present study show that the levels of serum HDL-C in a Mexican young population with normal-weight were higher in women than in men. This gender difference in HDL-C may be attributed to high endogenous estrogen levels in women, as it has been demonstrated that estrogen concentrations may increase HDL-C, which confers a protective effect of cardiovascular disease to premenopausal women [19]. However, also has been shown that the difference in HDL-C between women and men is an androgen effect, but not an estrogen effect, therefore, at puberty, concurrent with the rise in endogenous testosterone levels, the HDL-C levels in young men decline to the adulthood [20].

There was no significant difference in the levels of TC, TG, and LDL-C between genders. These findings are in agreement with previous studies in other populations [21-23]. In this research, oxLDL levels were higher in men than women; but there is a lack of published data about the oxLDL levels by gender. However, it has been shown that men have a higher oxidative stress compared to women, due to an increased generation of reactive oxygen species (ROS) and/or reduced activity of antioxidants, considering that under healthy conditions, cellular respiration in the mitochondria is the dominant source of ROS, therefore, a higher baseline metabolic rate in men than in women might contribute to a higher level of oxidative stress in men [24]. It is also known that an increase in oxLDL, as a consequence of increased oxidative stress and reduced antioxidant defenses, is a key event in the atherogenic process and a cardiovascular disease risk factor, which may be reflected in an increase in circulating levels of oxLDL [25].

CD36 gene is highly polymorphic; data from Ensembl Variation Build 60 (which is based on dbSNP Release 131) describe 2935 common genetic variants within $5 \mathrm{~kb}$ of the gene. Some involve putative transcription factor binding sites or sites in the 5 '-untranslated region, which are of potential significance because translational efficiency of the CD36 mRNA and thereby CD36 protein expression levels have been shown to be regulated by variants in the $5^{\prime}$-untranslated region [26]. A study on CD36 gene variants showed that subjects with GG homozygote genotype of the variant 80121259A > G (rs3211849) had a higher triglyceride level (99.16 \pm $2.61 \mathrm{mg} / \mathrm{dL})$ compared with non-carriers (89.27 \pm $1.45 \mathrm{mg} / \mathrm{dL}, P=0.001)$. In addition, compared with noncarriers, subjects with CT heterozygous and TT homozygous genotypes of the variant $80122878 \mathrm{C}>\mathrm{T}$ 


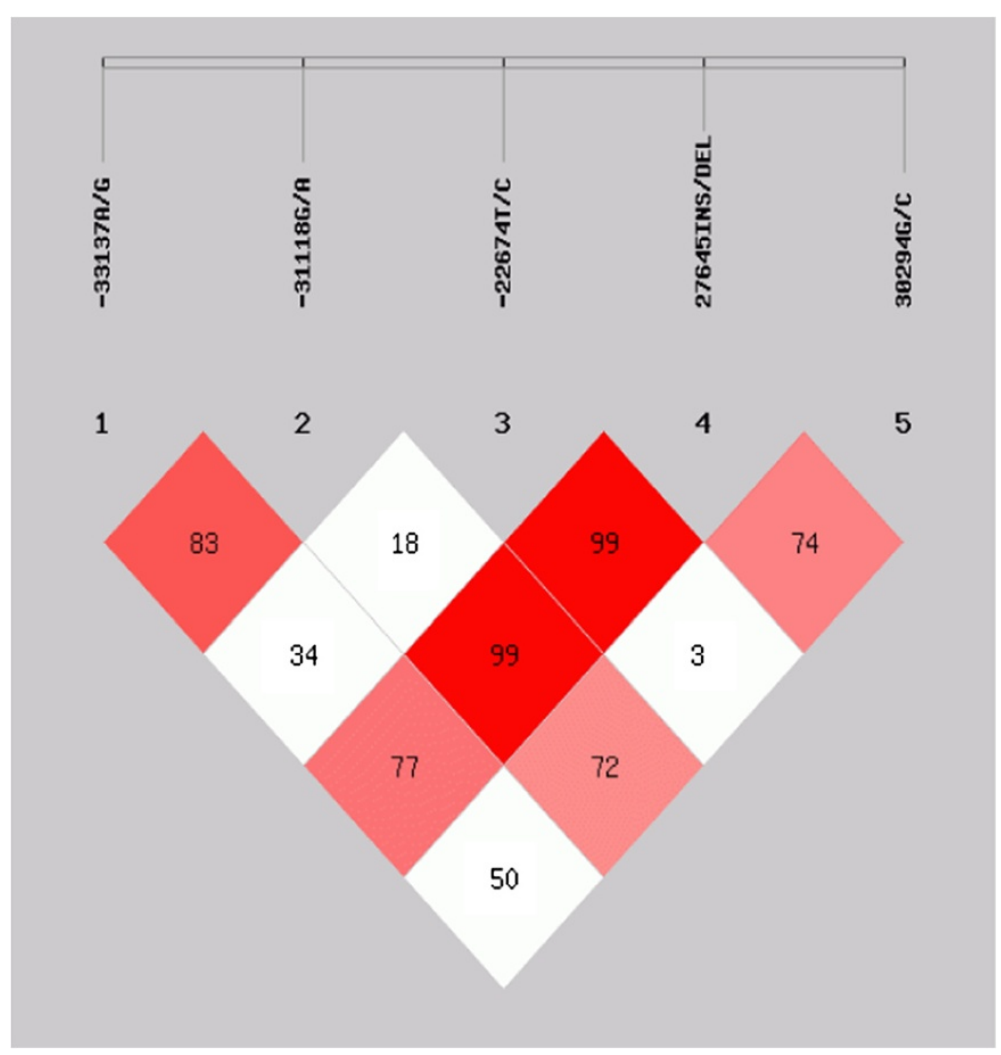

Figure 1 Linkage disequilibrium test of $C D 36$ gene polymorphisms ( $\left.D^{\prime}\right)$.

(rs1054516) had a significantly lower HDL-C level (46.6 \pm $0.46 \mathrm{mg} / \mathrm{dL}$ for non-carriers, $44.6 \pm 0.36 \mathrm{mg} / \mathrm{dL}$ for heterozygous, and $44.3 \pm 0.56 \mathrm{mg} / \mathrm{dL}$ for homozygous, $P=0.0008)$ [27].

Previous genetic studies showed various effects between CD36 locus and dyslipidemias, a genome-wide linkage scan among 418 individuals from 27 extended Mexican American families found two different locations on chromosome 7 were suggested as linked to susceptibility loci influencing in HDL cholesterol and triglycerides levels, however, it has been reported a major susceptibility locus in chromosome 15q influencing in TG levels in a Mexican American population [28]. In addition, among non-diabetic Mexican American families, quantitative trait locus study showed a strong linkage of two factors metabolic syndrome related, HDL-C and triglycerides to chromosome 7 (LOD score up to 3.2) [29].

A meta-analysis showed that CD36 gene locus (7p11q21.11) was significantly linked to triglycerides and triglycerides/HDL-C ratio, but not linked to LDL or total cholesterol [30]. In addition, a study in 61 CD36-deficient patients and 25 controls showed that the HDL-C concentrations in the CD36-deficient patients were significantly higher than in the control subjects, however, nondiabetic CD36-deficient patients had higher triglyceride concentrations than the control subjects, and triglyceride concentrations were higher in the diabetic CD36-deficient patients than in the nondiabetic CD36deficient patients [31].

In this research the genotype frequencies of each polymorphism were in Hardy-Weinberg equilibrium. However, genotype and allele frequencies found in this study for each of the polymorphisms in the CD36 gene are different to those reported in Caucasian population [32,33]. Mexicans are an admixed population, descended from a recent mix of Amerindian and European ancestry with a small proportion of African ancestry [34]. The influence of various races in our genetic background as Mexican population may explain the allele and genotype differences with respect to other populations.

In this study, the 27645Ins/Del polymorphism was found in high LD with polymorphisms -31118G/A, -22674 T/C and $30294 \mathrm{G} / \mathrm{C}$. These results were similar to those previously reported by Ma X, et al. in Caucasians [32].

Here we show an association between the CD36 polymorphisms and serum lipid levels in Mexican subjects. In this study, the subjects with -22674TC genotype had lower HDL-C levels than non-carriers. However, oxLDL levels were lower in the TT subjects; these results are different to those reported by Goyenechea et al., 2008 in the Spanish population, they shown that subjects carrying the CC genotype had higher levels of HDL-C and 
Table 3 Blood lipid profile according to CD36 polymorphisms

\begin{tabular}{|c|c|c|c|c|c|}
\hline Polymorphism & $\mathrm{TC}(\mathrm{mg} / \mathrm{dL})$ & $\mathrm{TG}(\mathrm{mg} / \mathrm{dL})$ & $\mathrm{HDL}-\mathrm{C}(\mathrm{mg} / \mathrm{dL})$ & LDL-C (mg/dL) & oxLDL (U/L) \\
\hline \multicolumn{6}{|l|}{$-33137 A / G$} \\
\hline AA & $150(140-178)$ & 70 (53-93) & $43(34-52)$ & $86(59-124)$ & 32 (26-39) \\
\hline$A G$ & $157(138-180)$ & $79(56-109)$ & $41(35-49)$ & $73(48-109)$ & $30(24-38)$ \\
\hline GG & $154(136-176)$ & $66(52-109)$ & $41(35-50)$ & $63(52-89)$ & $33(26-35)$ \\
\hline$P$ value & 0.64 & 0.40 & 0.88 & 0.19 & 0.70 \\
\hline \multicolumn{6}{|l|}{$-31118 \mathrm{G} / \mathrm{A}$} \\
\hline GG & $149(131-171)$ & $70(53-102)$ & $44(34-59)$ & $82(55-103)$ & $30(26-35)$ \\
\hline GA & $160(144-181)$ & 79 (63-109) & $41(36-48)$ & 75 (51-109) & $31(26-45)$ \\
\hline AA & $152(140-172)$ & 63 (53-95) & $42(34-51)$ & 87 (57-137) & $30(25-38)$ \\
\hline$P$ value & 0.18 & 0.09 & 0.71 & 0.20 & 0.34 \\
\hline \multicolumn{6}{|l|}{$-22674 \mathrm{~T} / \mathrm{C}$} \\
\hline$\pi$ & $152(137-169)$ & 65 (52-109) & $43(37-58)$ & 77 (51-114) & $28(25-35)$ \\
\hline TC & $154(138-179)$ & $77(62-102)$ & $38(32-48)$ & $89(61-116)$ & $34(28-43)$ \\
\hline CC & $153(145-175)$ & 71 (53-92) & $44(34-52)$ & $73(52-106)$ & $34(28-46)$ \\
\hline$P$ value & 0.66 & 0.71 & 0.04 & 0.60 & 0.01 \\
\hline \multicolumn{6}{|l|}{ 27645Ins/Del } \\
\hline Ins/Ins & 153 (139-179) & $72(53-103)$ & $42(34-50)$ & $78(55-105)$ & $31(26-38)$ \\
\hline Ins/Del & 152 (136-169) & $68(56-108)$ & $42(31-50)$ & $111(54-145)$ & $29(26-34)$ \\
\hline Del/Del & 149 (149-149) & $129(129-129)$ & $34(34-34)$ & $123(123-123)$ & - \\
\hline$P$ value & 0.66 & 0.43 & 0.60 & 0.31 & 0.51 \\
\hline \multicolumn{6}{|l|}{ 30294G/C } \\
\hline GG & $134(114-150)$ & 77 (63-107) & 46 (39-59) & $72(56-103)$ & $33(26-47)$ \\
\hline GC & $153(133-179)$ & $76(58-106)$ & $46(36-57)$ & $89(67-112)$ & $35(28-46)$ \\
\hline CC & $150(130-175)$ & $75(56-103)$ & $46(38-56)$ & $96(75-121)$ & $36(28-48)$ \\
\hline$P$ value & 0.06 & 0.89 & 0.76 & 0.03 & 0.72 \\
\hline
\end{tabular}

TC, Total cholesterol; TG, Triglyceride; HDL-C, High-density lipoprotein cholesterol; LDL-C, Low-density lipoprotein cholesterol; oxLDL, Oxidized low-density lipoprotein. The values were presented as median (percentile $5-95^{\text {th }}$ ). $P$ values among genotypes by Kruskal Wallis test.

lower LDL-C, this difference may be due to they did a study with dietary intervention where participants were under a low calorie diet for 8 weeks and the sample size, also their sample size was larger than ours, they concluded that the association with lower LDL-C level observed in response to the low calorie diet may devolve from reduced ability of $-22674 \mathrm{CC}$ homozygotes to take up fatty acids from the intestine, to synthesize triglycerides and secrete LDL-C. Our study also found that 30294CC carriers had higher LDL-C concentrations compared with subjects with the other genotypes; CC genotype was associated with high levels of free fatty acids in Caucasian population [9].

Although it is not clear how -33137A/G, -31118G/A -22674 T/C, 27645Ins/Del and 30294G/C polymorphisms can modulate lipid metabolism, has been demonstrated that $-22674 \mathrm{~T} / \mathrm{C}$ SNP is located upstream of the promoter, 14 bases 5 'of the transcription start site, which is a binding element for the transcriptional repressor GFI1B, this SNP was in complete LD with the -33137A/G SNP in Caucasians from the general population, thus so has been reported that the allele $\mathrm{A}$ at position $-33137 \mathrm{~A} / \mathrm{G}$ is in complete LD with the in $3(\mathrm{TG})_{13}$ variant, which determines the expression of an alternative spliced, inactive transcript lacking exons 4 and 5 [32]. In addition the allele $A$ of -31118 G/A SNP has been associated with reduced $\mathrm{CD} 36$ expression, lies between two alternative CD36 promoters, $1 \mathrm{C}$ and 1A [35]. It has been suggested that the 27645Ins/Del and 30294G/C polymorphisms located in the 3'-UTR could determine decreased mRNA stability [32].

In this research, five polymorphisms in the CD36 gene in haplotypes combinations were associated with high LDL-C and TC levels. This study showed that a haplotype analysis with five variants in the $C D 36$ receptor gene may explain the lipid profile variation more than a single variant. Similarly, in the Caucasian population have studied the five polymorphisms in the CD36 
Table 4 Association of CD36 haplotypes with lipid levels

\begin{tabular}{|c|c|c|c|c|}
\hline Haplotype & $\begin{array}{l}\text { Cases }(\mathrm{n}=96) \\
\text { LDL-C > } \\
100 \mathrm{mg} / \mathrm{dL}\end{array}$ & $\begin{array}{l}\text { Controls } \\
(n=134)\end{array}$ & OR (95\% Cl) & $P$ value \\
\hline AGTIG & $(0.046)$ & $(0.035)$ & $1.28(0.50-3.28)$ & 0.59 \\
\hline \multicolumn{5}{|l|}{11111} \\
\hline AGTIC & $(0.088)$ & $(0.081)$ & $1.06(0.54-2.08)$ & 0.84 \\
\hline \multicolumn{5}{|l|}{11112} \\
\hline AATIC & $(0.365)$ & $(0.340)$ & $1.08(0.73-1.61)$ & 0.68 \\
\hline \multicolumn{5}{|l|}{12112} \\
\hline AATDC & $(0.060)$ & $(0.019)$ & $3.25(1.12-9.40)$ & 0.02 \\
\hline \multicolumn{5}{|l|}{12122} \\
\hline AACID & $(0.116)$ & $(0.145)$ & $0.75(0.42-1.31)$ & 0.31 \\
\hline \multicolumn{5}{|l|}{12212} \\
\hline GGTIG & $(0.045)$ & $(0.099)$ & $0.42(0.19-0.92)$ & 0.02 \\
\hline \multicolumn{5}{|l|}{21111} \\
\hline GGTIC & $(0.042)$ & $(0.034)$ & $1.21(0.46-3.20)$ & 0.69 \\
\hline \multicolumn{5}{|l|}{21112} \\
\hline GGCIG & $(0.050)$ & $(0.086)$ & $0.55(0.25-1.19)$ & 0.12 \\
\hline \multicolumn{5}{|l|}{21211} \\
\hline GGCIC & $(0.112)$ & $(0.066)$ & $1.74(0.90-3.37)$ & 0.09 \\
\hline 21212 & & & & \\
\hline
\end{tabular}

\begin{tabular}{|c|c|c|c|c|}
\hline Haplotype & $\begin{array}{l}\text { Cases }(n=26) \\
\text { Cholesterol total > } \\
200 \mathrm{mg} / \mathrm{dL}\end{array}$ & $\begin{array}{l}\text { Controls } \\
(n=206)\end{array}$ & OR $(95 \% \mathrm{Cl})$ & $P$ value \\
\hline AGTIC & $(0.052)$ & $(0.087)$ & $0.60(0.16-2.15)$ & 0.43 \\
\hline \multicolumn{5}{|l|}{11112} \\
\hline AGCIC & $(0.031)$ & $(0.012)$ & $2.86(0.46-17.50)$ & 0.23 \\
\hline \multicolumn{5}{|l|}{11212} \\
\hline AATIC & $(0.472)$ & $(0.332)$ & $2.02(1.09-3.74)$ & 0.02 \\
\hline \multicolumn{5}{|l|}{12112} \\
\hline AATDC & $(0.020)$ & $(0.044)$ & $0.46(0.06-3.43)$ & 0.44 \\
\hline \multicolumn{5}{|l|}{12122} \\
\hline $\mathrm{AAClC}$ & (0.109) & $(0.131)$ & $0.85(0.33-2.13)$ & 0.72 \\
\hline \multicolumn{5}{|l|}{12212} \\
\hline GGTIG & $(0.021)$ & $(0.081)$ & $0.25(0.037-1.74)$ & 0.13 \\
\hline \multicolumn{5}{|l|}{21111} \\
\hline GGTIC & $(0.022)$ & $(0.039)$ & $0.58(0.086-3.95)$ & 0.57 \\
\hline \multicolumn{5}{|l|}{21112} \\
\hline GGCIG & $(0.083)$ & $(0.068)$ & $1.30(0.45-3.77)$ & 0.62 \\
\hline \multicolumn{5}{|l|}{21211} \\
\hline GGCIC & $(0.080)$ & $(0.088)$ & $0.94(0.32-2.74)$ & 0.92 \\
\hline 21212 & & & & \\
\hline
\end{tabular}

$1=$ Major allele, $2=$ minor allele. Markers: $-33137 \mathrm{~A} / \mathrm{G},-31118 \mathrm{G} / \mathrm{A},-22674 \mathrm{~T} / \mathrm{C}$, 27645Ins/Del, 30294G/C polymorphisms of CD36 gene. receptor gene and were found in high linkage disequilibrium and a common haplotype at the CD36 locus was associated with high free fatty acid levels and increased cardiovascular risk [32]. However, further investigations are needed to confirm our findings and demonstrate the mechanisms underlying such associations.

Nonetheless, the results of association studies must always be interpreted with caution, especially when multiple comparisons are performed, and replication in other populations is needed before a link between CD36 variants, dyslipidemias and cardiovascular disease.

Finally, some limitations of our study should be considered. Although this study had sufficient statistical power to detected large effects resulting from common alleles, the power to evaluate small effects due to rare alleles was limited. However, small genetic effects can be expected because of the complexity of lipid metabolism. Second, we could not completely exclude the influence of factors such as consumption of alcohol and tobacco on lipid levels.

\section{Conclusions}

The study provides evidence of a genetic association of CD36 haplotypes with the variability in LDL-C and TC levels in a sample of normal-weight subjects. The CD36 gene may be a candidate susceptibility to dyslipidemia in Mexican population.

\section{Methods \\ Subjects}

A total de 232 unrelated normal-weight subjects of 18 to 25 years old, from the state of Guerrero, Mexico. The participants were randomly selected considering their body mass index (BMI) of 18.5 to $24.9 \mathrm{~kg} / \mathrm{m}^{2}$. There were 157 women and 75 men, none of them had medication with lipid-lowering drugs such as statins or fibrates. The participants signed informed consent forms, and the protocol was approved by the Research Ethics Committee of the University of Guerrero.

\section{Blood pressure}

Blood pressure was measured in the sitting position with the use of an automatic sphygmomanometer on the left arm after 10 min rest. The systolic blood pressure (SBP) and diastolic blood pressure (DBP) were calculated from two readings with a minimal interval of $10 \mathrm{~min}$. Hypertension was defined as mean SBP $\geq 140 \mathrm{mmHg}$ and/or DBP $\geq 90 \mathrm{~mm} \mathrm{Hg}$ [36].

\section{Biochemical analysis}

A venous blood sample of $5 \mathrm{~mL}$ was obtained from each subject after at least a 12 hours fasting. All serum lipid levels and glucose were determined by enzymatic methods with commercially available kits (spinreact). 
Abnormal biochemical levels were identified when totalcholesterol $(\mathrm{TC})>200 \mathrm{mg} / \mathrm{dL}, \mathrm{TG} \geq 150 \mathrm{mg} / \mathrm{dL}, \mathrm{LDL}-\mathrm{C}>$ $100 \mathrm{mg} / \mathrm{dL}, \mathrm{HDL}-\mathrm{C}<40 \mathrm{mg} / \mathrm{dL}$ and glucose $>100 \mathrm{mg} / \mathrm{dL}$, based on the criteria of the National Cholesterol Education Program (NCEP) Expert Panel on Detection, Evaluation, and Treatment of High Blood Cholesterol in Adults (Adult Treatment Panel III) [5].

\section{Determination of serum oxLDL}

An enzyme-linked immunosorbant assay (ELISA) for oxLDL (Mercodia Oxidized LDL ELISA) was performed, according to the manufacturer's instructions using coated microtitration strips of 96-well plates, serum was diluted 1/6561, and incubated at room temperature for $2 \mathrm{~h}$ in plates precoated with oxLDL-lgG. After six washings, the plates were incubated with an antiapolipoprotein B (apoB) monoclonal antibody at room temperature for 30 minutes. After the removal of unbound conjugates by washing the samples six times, tetramethylbenzidine (TMB) was added to the wells as a chromogenic substrate. The mixture was incubated at room temperature in the dark for 15 minutes. Color development was stopped via a stopping solution, and absorbency was measured at $450 \mathrm{~nm}$ within 30 minutes. The oxLDL was calculated by constructing a standard curve using the standards included in the kit. The oxLDL concentrations in the samples were quantified in biomedical units as defined by the manufacturer.

\section{Genotyping}

Genomic DNA was extracted from leukocytes in samples of whole blood and was stored at $-20^{\circ} \mathrm{C}$ until analysis. Genotyping of the five polymorphisms -33137A/G (rs1984112), -31118G/A (rs1761667), -22674 T/C (rs2151916), 27645 Ins/Del (rs3840546) and 30294G/C (rs1049673) was performed by polymerase chain reaction and restriction fragment length polymorphism (PCR-RFLP). The five polymorphisms in the CD36 gene were selected for genotyping based on previously reported association with free fatty acids and triglycerides, whose minor allele frequency $>5 \%$ and one insertion/ deletion polymorphism [32]. Primers for the polymorphims were designed and restriction enzymes (REs) were identified using the Primer 3 and NEB cutter softwares respectively. Unique National Center for Biotechnology Information (NCBI) Build 37 chromosome and base pair locations may be obtained from Ensembl Variation Build 59 (which is based on dbSNP Release 131). Details including the location of polymorphisms in the CD36 gene, primer sequences and REs with product sizes are presented in Table 5.

Each reaction system of a total volume of $24 \mu \mathrm{L}$, containing $100 \mathrm{ng}$ of genomic DNA, $0.2 \mathrm{mM}$ of each primer, $0.2 \mathrm{mM}$ dNTPs, and 2.0U of Taq polymerase (Invitrogen Life Technologies). The PCR products were digested with the respective restriction enzymes, and were visualized on $6 \%$ polyacrylamide gels stained with silver nitrate $2 \%$.

Table 5 - Characteristics of the polymorphisms studied in the CD36 gene

\begin{tabular}{|c|c|c|c|c|}
\hline Polymorphisms & Primer sequence & Annealing temp. $\left({ }^{\circ} \mathrm{C}\right)$ & Product size (bp) & Restriction enzyme/allele sizes \\
\hline \multirow[t]{2}{*}{$-33137 A / G$} & F: 5'-CATGCAGCTCTGTTTTATGTGAG-3' & 60 & 159 & Msel \\
\hline & & & & AA $67,56,29,7$ \\
\hline \multirow[t]{2}{*}{ (rs1984112) } & R: 5'-CCCCATCTCTTAGGCCCGTGACA-3' & & & AG $85,67,56,29,7$ \\
\hline & & & & GG $85,67,7$ \\
\hline \multirow[t]{2}{*}{$-31118 \mathrm{G} / \mathrm{A}$} & F: 5'-CAAAATCACAATCTATTCAAGACCA-3' & 58 & 190 & Hhal \\
\hline & & & & AA 190 \\
\hline \multirow[t]{2}{*}{ (rs1761667) } & R: 5'-TTTTGGGAGAAATTCTGAAGAG-3' & & & GA $190,138,52$ \\
\hline & & & & GG 138, 52 \\
\hline \multirow[t]{2}{*}{$-22674 \mathrm{~T} / \mathrm{C}$} & F: 5-'TCTTGCTGGGCCCTGCCCA-3' & 68 & 452 & Hpy 1881 \\
\hline & & & & Tा 452 \\
\hline \multirow[t]{2}{*}{ (rs2151916) } & R: 5'-TGTTTGCCCCAAGTGCTGGGTC-3' & & & TC 452, 430, 22 \\
\hline & & & & CC 430, 22 \\
\hline \multirow[t]{2}{*}{ 27645Ins/Del16 } & F: 5'-GGGACCATTGGTGATGAGAAGG-3' & 68 & 563 & Ins/Ins \\
\hline & & & 563,547 & Ins/Del \\
\hline (rs3840546) & R: 5'-TTGGAAAATGCACGGCCAGCA-3' & & 547 & Del/Del \\
\hline \multirow[t]{2}{*}{ 30294G/C } & F: 5'-ACGCTTGGCATCTTCAGAATGCT-3' & 60 & 465 & Mnll \\
\hline & & & & GG 331, 134 \\
\hline \multirow[t]{2}{*}{ (rs1049673) } & R: 5'TGAACCCCTGCTCAAGAAACAGAGT-3' & & & GC 331, 265, 134, 66 \\
\hline & & & & CC $265,134,66$ \\
\hline
\end{tabular}




\section{Statistical analysis}

The statistical analyses were done with the statistical software package SPSS 15.0 and STATA software 9.0. Quantitative variables were expressed as medians and $25^{\text {th }}$ to $75^{\text {th }}$ percentiles or $5^{\text {th }}$ to $95^{\text {th }}$ percentiles; the significance of differences between groups was determined using Wilcoxon-Mann Whitney or Kruskal Wallis test. Qualitative variables were expressed as percentages. Allele and genotype frequencies were determined by calculating Hardy-Weinberg equilibrium, difference in genotype distribution between the groups female and male was obtained using the chi-square test, a $P$ value of less than 0.05 was considered statistically significant. For analysis linkage disequilibrium of polymorphisms in CD36 gene and the association between haplotypes and lipid phenotypes were analysed using the software program SHEsis (http:// analysis.bio-x.cn/myAnalysis.php) [37].

\section{Competing interests}

HBM is Editor-in-Chief of the Journal of Foot and Ankle Research. It is journal policy that editors are removed from the editorial decision making processes for papers they have co-authored. The remaining authors declare that they have no competing interests.

\section{Authors' contributions}

LERA carried out genetic analysis and writing the manuscript. ABSB performed laboratory measurements and quality control. IPGG performed the statistical analysis. LSG and JFMV participated in the critical revision of the manuscript. IPR conceived the study and participated in manuscript preparation. All authors read and approved the final manuscript.

\section{Acknowledgements}

We are grateful to Samuel García-Arellano for his technical assistance. This study was supported by grants of the Fondo SEP-CONACyT (No. 106734) and Programa de Fortalecimiento Académico del Posgrado de Alta Calidad (1010/ 455/2013 C-677/2013). LERA received a fellowship of CONACyT (No. 236905).

\section{Author details}

${ }^{1}$ Laboratorio de Investigación en Obesidad y Diabetes, Unidad Académica de Ciencias Químico Biológicas, Universidad Autónoma de Guerrero, Chilpancingo, Guerrero, México. ²Departamento de Biología Molecular y Genómica, Instituto de Investigación en Ciencias Biomédicas, Centro Universitario de Ciencias de la Salud, Universidad de Guadalajara, Jalisco, México.

Received: 9 September 2013 Accepted: 31 October 2013

Published: 5 November 2013

\section{References}

1. Yin RX, Li YY, Lai CQ: Apolipoprotein A1/C3/A5 haplotypes and serum lipid levels. Lipids Health Dis 2011, 10:140.

2. Wasan KM, Brocks DR, Lee SD, Barrable KS, Thornton SJ: Impact of lipoproteins on the biological activity and disposition of hydrophobic drugs: implications for drug discovery. Nat Rev Drug Discov 2008, 7:84-97.

3. Hachem SB, Mooradian AD: Familial Dyslipidaemias: an Overview of Genetics, Pathophysiology and Management. Drugs 2006, 66(15):1949-1969.

4. Alvim RO, Freitas SR, Ferreira NE, Santos PC, Cunha RS, Mill JG, Krieger JE, Pereira AC: APOE polymorphism is associated with lipid profile, but not with arterial stiffness in the general population. Lipids Health Dis 2010, 9:128.

5. National Cholesterol Education Program (NCEP) Expert Panel on Detection, Evaluation, and Treatment of High Blood Cholesterol in Adults (Adult Treatment Panel III). Circulation 2002, 106(25):3143-3421.

6. Gautam S, Banerjee M: The macrophage Ox-LDL receptor, CD36 and its association with type II diabetes mellitus. Mol Genet Metab 2011, 102:389-398.
7. Chen K, Frebbraio M, Li W, Silverstein RL: A specific CD36-dependent signaling pathway is required for platelet activation by oxLDL. Cir Res 2008, 102(12):1512-1519.

8. Kar NS, Ashraf MZ, Valiyaveettil M, Podrez EA: Mapping and characterization of the binding site for specific oxidized phospholipids and oxidized low density lipoprotein of scavenger receptor CD36. J Bio/ Chem 2008, 283(13):8765-8771.

9. Love-Gregory L, Sherva R, Schappe T, Qi JS, McCrea J, Klein S, Connelly MA Abumrad NA: Common CD36 SNPs reduce protein expression and may contribute to a protective atherogenic profile. Hum Mol Genet 2011, 20(1):193-201.

10. Kondo N, Honda S, Kuno S, Negi A: Positive association of common variants in CD36 with neovascular age-related macular degeneration. Aging 2009, 1(2):266-274.

11. Drover VA, Ajmal M, Nassir F, Davidson NO, Nauli AM, Sahoo D, Tso P, Abumrad NA: CD36 deficiency impairs intestinal lipid secretion and clearance of chylomicrons from the blood. J Clin Invest 2005, 115:1290-1297.

12. Bokor S, Legry V, Meirhaeghe A, Ruiz JR, Mauro B, Widhalm K, Manios Y, Amouyel P, Moreno LA, Molnàr D, Dallongeville J, HELENA Study group: Single-nucleotide polymorphism of CD36 locus and obesity in European adolescents. Obesity 2010, 18(7):1398-1403.

13. Yamashita S, Hirano K, Kuwasako T, Janabi M, Toyama Y, Ishigami M, Sakai $\mathrm{N}$ : Physiological and pathological roles of a multi-ligand receptor CD36 in atherogenesis; insights from CD36-deficient patients. Mol Cell Biochem 2007, 299:19-22

14. Noel SE, Lai C, Mattei J, Parnell LD, Ordovas JM, Tucker KL: Variants of the CD36 Gene and metabolic syndrome in Boston Puerto Rican adults. Atherosclerosis 2010, 211(1):210-215.

15. Geloen A, Helin L, Geeraert B, Malaud E, Holvoet P, Marguerie G: CD36 Inhibitors reduce postprandial hypertriglyceridemia and protect against diabetic dyslipidemia and atherosclerosis. PLOS ONE 2012, 7(5):e37633. 10.1371/journal.pone.0037633.

16. Rac ME, Safranow K, Poncyljusz W: Molecular basis of human gene mutations. Mol Med 2007, 13(5-6):288-296.

17. Banerjee M, Gautam S, Saxena M, Kumar H, Agrawal C: Association of CD36 gene variants rs1761667 (G > A) and rs1527483 (C > T) with Type 2 diabetes in North Indian population. Int J Diab Mellitus 2010, 12(3):179-183. doi:10.1016/j.ijdm.2010.08.002.

18. Pravenec M, Kurtz TW: Molecular genetics of experimental hypertension and the metabolic syndrome: from gene pathways to new therapies. Hypertension 2007, 49:941-952.

19. Eapen DJ, Kalra GL, Rifai L, Eapen CA, Merchant N, Khan BV: Raising HDL cholesterol in women. Int J Womens Health 2010, 1:181-191.

20. Rossouw JE: Hormones, genetic factors, and gender differences in cardiovascular disease. Cardiovasc Res 2002, 53(3):550-557.

21. Kolovou GD, Anagnostopoulou KK, Damaskos DS, Bilianou HI, Mihas C, Milionis HJ, Kostakou PM, Cokkinos DV: Gender differences in the lipid profile of dyslipidemic subjects. Eur J Intern Med 2009, 20(2):145-151.

22. Jimoh K, Adediran S, Agboola M, Busari A, Idowu A, Adeoye A, Adebisi A: Lipid profile of type 2 diabetic patients at a rural tertiary hospital in Nigeria. J Diabetes Endocrinol 2012, 1(4):46-51.

23. Carnevale GP, Fra GP, Colli E, Bigliocca M, Mella R, Scaglia E, Bartoli E: Sex differences in lipid profiles in relation to the progression of glucose abnormalities. J Diabetes 2012, 4:95-101.

24. Ide T, Tsutsui H, Ohashi N, Hayashidani S, Suematsu N, Tsuchihashi M, Tamai $H$, Takeshita A: Greater oxidative stress in healthy young men compared with premenopausal women. Arterioscler Thromb Vasc Biol 2002, 22(3):438-442.

25. João M, Brandão J, Santos A, Coimbra S: Adipokines, Oxidized Low-Density Lipoprotein, and C-Reactive Protein Levels in Lean, Overweight, and Obese Portuguese Patients with Type 2 Diabetes. ISRN Obes 2013, 142097:7. doi:10.1155/2013/142097.

26. Ghosh A, Murugesan G, Chen K, Zhang L, Wang Q, Febbraio M: Platelet CD36 surface expression levels affect functional responses to oxidized LDL and are associated with inheritance of specific genetic polymorphisms. Blood 2011, 117(23):6355-6366.

27. Chien KL, Hsu HC, Liu PH, Lin HJ, Chen MF: Common sequence variants in CD36 gene and the levels of triglyceride and high-density lipoprotein cholesterol among ethnic Chinese in Taiwan. Lipids Health Dis 2012, $11: 174$. 
28. Duggirala R, Blangero J, Almasy L, Dyer TD, Williams KL, Leach RJ, O'Connell P, Stern MP: A major susceptibility locus influencing plasma triglyceride concentrations is located on chromosome $15 q$ in Mexican Americans. Am J Hum Genet 2000, 66(4):1237-1245.

29. Arya R, Blangero J, Williams K, Almasy L, Dyer TD, Leach RJ, O'Connell P, Stern MP, Duggirala R: Factors of insulin resistance syndrome-related phenotypes are linked to genetic locations on chromosomes 6 and 7 in nondiabetic Mexican-Americans. Diabetes 2002, 51(3):841-847.

30. Malhotra A, Elbein SC, Ng MC, Duggirala R, Arya R, Imperatore G, Adeyemo A, Pollin TI, Hsueh WC, Chan JC, Rotimi C, Hanson RL, Hasstedt SJ, Wolford JK: Meta-analysis of genome-wide linkage studies of quantitative lipid traits in families ascertained for type 2 diabetes. Diabetes 2007, 56(3):890-896.

31. Furuhashi M, Ura N, Nakata T, Shimamoto K: Insulin sensitivity and lipid metabolism in human CD36 deficiency. Diabetes Care 2003, 26(2):471-474.

32. Ma X, Bacci S, Mlynarski W, Gottardo L, Soccio T, Menzaghi C, lori E, Lager RA, Shroff AR, Gervino EV, Nesto RW, Johnstone MT, Abumrad NA, Avogaro A, Trischitta V, Doria A: A common haplotype at the CD36 locus is associated with high free fatty acid levels and increased cardiovascular risk in Caucasians. Hum Mol Genet 2004, 13(9):2197-2205.

33. Goyenechea E, Collins LJ, Parra D, Liu G, Snieder H, Swaminathan R, Spector TD, Martínez JA, O'Dell SD: CD36 gene promoter polymorphisms are associated with low density lipoprotein-cholesterol in normal twins and after a low-calorie diet in obese subjects. Twin Res Hum Genet 2008, 11(6):621-628

34. Silva I, Price AL, Patterson N, Yu F, Cox DR, Waliszewska A, McDonald GJ, Tandon A, Schirmer C, Neubauer J, Bedoya G, Duque C, Villegas A, Bortolini MC, Salzano FM, Gallo C, Mazzotti G, Tello-Ruiz M, Riba L, Aguilar-Salinas CA, Canizales-Quinteros S, Menjivar M, Klitz W, Henderson B, Haiman CA, Winkler C, Tusie-Luna T, Ruiz-Linares A, Reich D: A genomewide admixture map for Latino populations. Am J Hum Genet 2007, 80(6):1024-1036.

35. Pepino MY, Love-Gregory L, Klein S, Abumrad NA: The fatty acid translocase gene $C D 36$ and lingual lipase influence oral sensitivity to fat in obese subjects. J Lipid Res 2012, 53(3):561-566.

36. 1999 World Health Organization-International Society of Hypertension Guidelines for the Management of Hypertension. Guidelines Subcommittee. J Hypertens 1999, 17(2):151-183.

37. Shi YY, He L: SHEsis, a powerful software platform for analyses of linkage disequilibrium, haplotype construction, and genetic association at polymorphism loci. Cell Res 2005, 15:97-98.

doi:10.1186/1476-511X-12-167

Cite this article as: Ramos-Arellano et al:: CD36 haplotypes are associated with lipid profile in normal-weight subjects. Lipids in Health and Disease 2013 12:167.

\section{Submit your next manuscript to BioMed Central and take full advantage of:}

- Convenient online submission

- Thorough peer review

- No space constraints or color figure charges

- Immediate publication on acceptance

- Inclusion in PubMed, CAS, Scopus and Google Scholar

- Research which is freely available for redistribution 